\title{
154 ANOS DE FERROVIAS NO BRASIL: PARA ONDE CAMINHA ESSE TREM?
}

\author{
Dilma Andrade de Paula* \\ dpaula@inhis.ufu.br
}

RESUMO: A proposta deste artigo é investigar as principais modificações operadas na política ferroviária em relação ao transporte inter-regional de passageiros e de cargas. À criação da Rede Ferroviária Federal, em 1957, unificando dezoito empresas, o "novo" Estado pós-1990 respondeu com a reprivatização da malha, reformulando também as agências de controle e execução da política. A que interesses respondem essas mudanças? Quais as características da política ferroviária brasileira constituída nesse período? São questões intrincadas, que envolvem o formato de Estado (em termos de sociedade política), a sua relação com o mercado, a questão da globalização financeira, o panorama interno da luta de classes etc, que exigem estudos mais detalhados e comprometidos com o entendimento desse setor no desenvolvimento do capitalismo no Brasil.

Palavras-chave: Política de transportes, ferrovias, Rede Ferroviária Federal S.A.

Em 2004, completou-se o sesquicentenário das ferrovias brasileiras. O que restou de toda a complexa história ferroviária? Qual o seu papel social? E os trabalhadores ferroviários, onde estão e como têm sido suas trajetórias? E a documentação sobre as ferrovias? E os trens de passageiros intermunicipais e interestaduais? Pesquisar sobre as empresas ferroviárias e sobre os ferroviários é quase um trabalho arqueológico, à procura dos sinais e dos poucos vestígios que nos restaram, enfrentando arquivos "mortos" e porões. Na música, na literatura, nas memórias individuais, na rica trajetória dos trabalhadores ferroviários, nas estações e pátios país afora, a lembrança dos trens permanece, sinais da latência da memória em luta contra o esquecimento.

Parece exaustivo e senso comum sempre que se trata de ferrovias fazer um histórico mas, neste artigo, o objetivo de um breve histórico é

\footnotetext{
* Professora do Instituto de História da Universidade Federal de Uberlândia.
} 
recuperar uma visão mais geral desse processo. A complexidade das conjunturas políticas e sociais, bem como os aspectos relacionados à trajetória dos ferroviários somente serão abordados tangencialmente, já que exigiriam um outro trabalho.

A partir da década de 1830 surgiram as primeiras leis de incentivo à construção ferroviária, mas apenas vinte anos depois as ferrovias começaram a ser construídas. A expansão da rede ferroviária ligou-se, sobretudo, à necessidade de exportação do café, que exigiu também um programa de melhoria dos portos como os de Manaus, Belém e Rio de Janeiro. Pouco se fala, se escreve e quase nada se guardou sobre o trabalho dos ferroviários nesse período, heróis anônimos, cujas histórias se perderam no tempo. Ao contrário, um nome sempre lembrado em todos os históricos das ferrovias, principalmente os oficiais, é o do financista e industrial Irineu Evangelista de Souza, Barão e Visconde de Mauá, responsável pelo empreendimento do primeiro trecho ferroviário brasileiro e consagrado como o patrono do Ministério dos Transportes. Somente no dia 30 de abril de 1854 é que se concluiu a primeira parte desse trajeto ferroviário, com bitola de 1.676 metros e extensão de 14,5 quilômetros, entre a praia, depois chamada Porto Mauá, e a localidade de Fragoso, a 1.733 quilômetros da raiz da Serra de Petrópolis. $\mathrm{O}$ trem inaugural, composto de locomotiva, três carros de passageiros e um de bagagem, fez o percurso até o ponto terminal do trecho em 25 minutos, com velocidade média de $35 \mathrm{~km} / \mathrm{h}$. Muitos anos depois, essa velocidade ainda continuava lenta.

Avançando os trilhos território adentro, outras ferrovias foram construídas ainda no século XIX, associadas, principal mas não exclusivamente, à economia agro-exportadora. Houve uma diversidade muito grande de experiências, que tem sido ressaltada em diversos trabalhos mais recentes, rompendo marcos historiográficos simplificadores e mais tradicionais (PAULA, 2006). O trabalho de Flávio Saes (1981), referência obrigatória nas pesquisas, especialmente sobre as ferrovias paulistas, abordou não só a relação café-ferrovias, mas também o início da crise de três grandes empresas: a Paulista, a Mogiana e a Sorocabana. Diretamente associadas à economia cafeeira, essas ferrovias sofreram também um débâcle com a queda dos preços do café, já que tiveram um desenvolvimento interdependente do mercado cafeeiro. A conclusão de Saes apontou que, embora tivessem surgido novos produtos com fluxos remuneradores, não foram tão lucrativos quanto o café. Com a estatização das ferrovias (na década de 1950), o Estado passou a administrar um sistema em franco declínio, situação então comum às ferrovias brasileiras em geral: "o declínio das empresas (derivado 
das condições do tráfego) precede e determina a estatização das empresas. Portanto, o Estado teria passado a administrar estradas de ferro das quais nada se poderia esperar além do 'permanente regime deficitário' que as caracterizou" (SAES, 1981, p. 188).

O período de maior expansão das construções ferroviárias ocorreu de 1908 a 1914. Somente em 1910, foram construídos 2.225 quilômetros de ferrovias, sucesso nunca mais atingido. Mas, já em 1901, o governo brasileiro iniciou a operação de resgate de doze ferrovias estrangeiras beneficiárias da garantia de juros (a maioria delas nas regiões Sul e Nordeste). Como a dívida externa pesava sobre a economia brasileira, o governo reconsiderava a garantia obtida com as Leis de 1852 (que concedia juros de 5\% sobre o capital) e as de 1857 (que os elevava para 7\%), porque esses incentivos provocavam um rombo nos cofres públicos, que sempre precisavam cobrir a diferença que as administrações privadas não se empenhavam em obter na exploração das estradas. Terreno favorável ao capital bancário-financeiro internacional, o investimento em ferrovias costumava ser menos um investimento produtivo e muito mais uma aplicação de caráter financeiro $\left(\mathrm{N}_{\mathrm{A}-}\right.$ TAL, 1991, p. 67-68).

Geralmente, as empresas ferroviárias criadas operavam conjuntamente o tráfego de passageiros e de cargas. A relação social que se estabeleceu nas construções e operações de linhas de passageiros é que foi capaz de deixar profundas marcas nas memórias, seja pela rejeição (a expropriação de terrenos para construção do leito férreo, por exemplo), seja pela aceitação, pela novidade e possibilidade de transportar mercadorias e pessoas para vários locais (PAULA, 2004). A operação de trens de passageiros envolvia contatos permanentes da empresa e de ferroviários com as populações ao seu redor, de forma que as alterações no cotidiano dos locais por onde passavam os trens eram visíveis: a construção e movimentação de estações e pontos de paradas, o tráfego constante de passageiros e de mercadorias avulsas, as ligações regionais e inter-regionais, os movimentos dos trabalhadores ferroviários (engenheiros, agentes de estação, telegrafistas, trabalhadores braçais que atuavam na construção e conservação das linhas, especialistas das oficinas etc.) que se deslocavam sempre, de município em município. Havia todo um movimento em torno da ferrovia que, via de regra, atravessava as cidades e impunha sua presença, muito diferente do que acontece com os trens de cargas atualmente em operação, que atravessam suas imensas composições silenciosamente, nas periferias das cidades e das áreas produtoras para os entroncamentos e portos. As estações geralmente se localizam nas periferias, empregam um efetivo bem menor e me- 
nos complexo de trabalhadores, ficando, portanto, longe daquele burburinho pulsante dos "encontros e despedidas". Esse transporte, que agregava cargas e passageiros, com o passar do tempo foi divorciando esses "clientes", priorizando o primeiro em detrimento do segundo.

Durante o Governo Vargas, no final da década de 1930, iniciou-se um processo de encampação de empresas ferroviárias e de seus prejuízos, com o objetivo de reorganizar administrativamente as empresas, modernizar linhas e material rodante. Até os anos 20, houve um boom de construções ferroviárias, à sombra dos subsídios governamentais. Com o passar do tempo, as empresas que se beneficiaram dos bônus da implantação, não arcaram com o ônus dos investimentos necessários ao seu funcionamento. Ficava relegada ao passado a era das construções ferroviárias, e a sua operação, cada vez mais, sucateada. Em algumas regiões, a ferrovia lançou seus lastros sociais e foi apropriada pela população, a despeito da forma como foi constituída: sem haver um plano efetivo nacional de malha ferroviária integrada. Todavia, fez ligações regionais e propiciou o acesso ao transporte de mercadorias que serviam ao incremento do mercado interno, além do transporte de pessoas.

A administração ferroviária ficava a cargo da Inspetoria Federal de Estradas (IFE), órgão do Ministério da Viação e Obras Públicas, encarregado de gerir também as rodovias federais. Em 1937 foi criado o Departamento Nacional de Estradas de Rodagem (DNER) e, em 1941, o Departamento Nacional de Estradas de Ferro (DNEF), extinto em 1974, quando suas funções foram transferidas para a Secretaria-Geral do Ministério dos Transportes e parte para a Rede Ferroviária Federal S.A. (RFFSA).

As modificações na tração também influenciaram a lenta evolução do setor e sua diferenciação. Ainda hoje, nos trens turísticos, predomina a "Maria-fumaça", recurso ao saudosismo e busca de certa aura romântica dos primeiros tempos (vista pelos olhos de hoje). Em 1930, houve a introdução da tração elétrica, substituindo a tração a vapor em alguns trechos e, em 1939, introduziu-se a diesel elétrica, também em algumas empresas. Todavia, somente após 1950, a diesel foi utilizada mais intensivamente. A criação da Companhia Vale do Rio Doce, em 1942, tornou-se também um marco histórico dessa evolução, pois absorveu a Estrada de Ferro VitóriaMinas (construída a partir de 1903) e prosseguiu modernizando-se - ao contrário da maior parte das empresas - para suportar o pesado tráfego de minério de ferro entre as jazidas de Itabira, em Minas Gerais, e o Porto de Vitória, no Espírito Santo. 
Na esteira do desenvolvimentismo, a partir de meados de 1950, aumentou a entrada de maciços investimentos estrangeiros, principalmente de capital norte-americano, disponível após o financiamento da recuperação econômica dos países europeus, destruídos pela Segunda Guerra Mundial. Consolidava-se, então, a passagem de uma economia voltada para a produção e exportação de produtos primários para outra mais voltada para o mercado interno, tendo na indústria seu carro-chefe. A mudança de eixo econômico arrastou consigo grande parte das ferrovias que, construídas em função do modelo agroexportador, começaram a sofrer um processo maior de desgaste, principalmente aquelas que operavam transporte de passageiros, numa época em que eram necessários investimentos pesados para a modernização dos equipamentos, correção de traçados e adaptação aos novos rumos econômicos.

Nos projetos governamentais e nos meios técnicos e políticos decisórios do país, a construção de rodovias e a implementação do transporte rodoviário, de pessoas e de cargas, assumiram a preponderância sobre os demais modais. Desde a década de 1920, o debate relativo aos meios de transportes, centrou-se na oposição ferrovia/rodovia, não se estabelecendo um efetivo projeto nacional e integrado de transportes (PAULA, 2006). A mudança preferencial para as rodovias, como principal veículo de integração nacional, não foi simples, pois envolvia toda uma nova configuração política e cultural em benefício do automóvel, tornando a ferrovia sinônimo do atraso. Com exceção dos trens suburbanos, os inter-regionais desapareceram progressiva e silenciosamente.

Entre 1955 e 1959, entraram no país quase 400 milhões de dólares, dos quais $48,6 \%$ originavam-se dos EUA. Do total dos investimentos, $53,9 \%$ foram aplicados no setor de máquinas-automóveis, contribuindo, assim, para consolidar a indústria automobilística como líder absoluta do processo de industrialização (DoURADo, 1984, p. 734). Sob o Plano de Metas, o governo Juscelino Kubitschek (1956-1960) investiu pesado na atração e implantação da indústria automobilística, tentando provocar um efeito cascata sobre todo o parque produtivo, o que incrementou a construção de estradas, o setor de máquinas, equipamentos e auto-peças. $\mathrm{O}$ ingresso maciço de investimentos estrangeiros veio acompanhado da progressiva criação e consolidação da indústria automobilística e das grandes empreiteiras de obras públicas (PAULA, 2000, p. 203-207). A ferrovia deixava de ser objeto de investimentos internacionais - em contraposição a projetos rodoviárioautomobilísticos - e passava a ser alvo de projetos de extinção e desativação, sobretudo de ramais dedicados ao transporte inter-regional de passageiros. 
Um sintoma dessa política é o decréscimo do volume de investimentos do Banco Nacional de Desenvolvimento Econômico (BNDE), que, na sua maioria, constituíram-se de aditamentos e complementação de recursos destinados a projetos aprovados entre 1952 e 1955. De 1957 em diante, os investimentos do Banco no setor foram sensivelmente diminuídos, variando de ano para ano. No geral, o setor ferroviário foi o que apresentou pior desempenho em todo o período do governo Juscelino Kubitschek. Em termos de investimentos brutos em transporte, essa foi a tendência que permaneceu: em 1960, o transporte rodoviário recebia $76,4 \%$ (rodovia, $28 \%$ e veículos, $48,4 \%$ ) e o transporte ferroviário recebia 7,9\% (LESSA apud NATAL, 1991, p. 143). Para Jorge Natal, ficava então impossível a "definição de uma nova política ferroviária no jogo concreto dos interesses econômicos estabelecidos" (NATAL, 1991, p. 154):

A opção politicamente posicionada era a rodoviário-automobilística. Ela articulava os interesses das montadoras e de outras frações do capital forâneo e de várias frações do capital nacional, sob a égide do Estado que, do ponto de vista produtivo, "entrava" com suas companhias siderúrgicas, petrolifera etc.

Daí pode-se entender, por exemplo, por que as ferrovias não foram capazes de catalisar investimentos e interesses das nascentes empreiteiras. À perda econômica, junta-se a elaboração cultural centrada no automóvel, divulgada em amplos canais da sociedade civil. Esse processo foi alimentado pela decadência do transporte ferroviário, vitimado pelo abandono progressivo. Houve, também a partir do governo JK, uma reconfiguração regional, deslocando o pólo de desenvolvimento para a região Centro-Oeste, a partir da construção de Brasília. Aquelas antigas áreas produtoras de café, por exemplo, em algumas sub-regiões do Sudeste (Noroeste do Rio de Janeiro e Zona da Mata de Minas Gerais, para citar somente algumas), são relegadas e até consideradas sem expressão econômica (PAULA, 2000). As ferrovias que atravessavam e ligavam essas regiões acabam por tornar-se alvo das desativações, igualmente consideradas "antieconômicas". Se, por um lado, o desenvolvimentismo propicia a integração em outro eixo espacial, rompendo com a herança das antigas "ilhas", por outro lado, provocou novos desequilíbrios regionais e inter-regionais, pois tratava-se de um desenvolvimentismo conservador, constituído em bases muito excludentes (ARAújo, 1999, p. 168).

No Relatório do Ministério de Viação e Obras Públicas (MVOP), sob a regência de Lúcio Meira, o combate ao déficit ferroviário era o mote cen- 
tral. A criação da Rede Ferroviária Federal S.A., empresa de economia mista, vinculada ao MVOP, veio responder à propalada necessidade de reorganizar a administração ferroviária, visando combater os déficits. A discussão sobre o projeto da RFFSA, processo importante e ainda a ser estudado, iniciou-se no governo Vargas, como uma das principais sugestões da Comissão Mista Brasil-Estados Unidos (1952), para a criação de uma empresa de sociedade anônima, com a finalidade de coordenar as empresas ferroviárias da União. A existência de uma empresa estatal aglutinadora de ferrovias federais era fato em vários países europeus desde o final do século XIX, segundo Margareth Martins (1994, p. 357): Áustria, 1851; Bélgica, 1843; Dinamarca, 1885. A Société Nationale des Chemins de Fer (SNCF), francesa, que sobrevive até os dias de hoje, foi constituída em 1938. Assim, a criação da RFFSA respondia a uma tendência mundial em termos de administração ferroviária e de intervencionismo estatal e dando continuidade a uma tendência já iniciada no Brasil desde o início do século, por meio da encampação de empresas. O projeto, debatido no Clube de Engenharia, ${ }^{1}$ tramitou durante anos no Congresso, provocou acalorados debates entre estatistas e privatistas, sendo regulamentado e aprovado durante o governo JK, sob a forma da Lei n. 3.115, de 16 de março de $1957 .^{2}$

Os principais acionistas da RFFSA eram o Governo Federal (87\%), os Estados (10,2\%) e os Municípios (2,66\%). Sua estrutura administrativa consistia de três instâncias principais: a) um colegiado de sete diretores, inclusive o presidente; $b$ ) o presidente e os departamentos executivos; $c$ ) as unidades de operação e as outras subsidiárias. O Presidente era, na verdade, o chefe executivo; alguns diretores exerciam também funções executivas e outros atuavam como consultores em áreas específicas. Ao colegiado de diretores cabia a administração da empresa (Geipot, Coverdalle \& ColPITTS, 1967, p. 9-29). A operação do sistema ferroviário não era prerrogativa exclusiva da Rede Ferroviária. O Conselho Nacional de Transportes (CNT), o DNEF e a Contadoria Geral dos Transportes (CGT) também elaboravam a política geral do setor.

Em 1959, o Relatório anual da RFFSA indicava que os dois objetivos centrais da empresa eram a correção da insuficiência crônica dos transportes ferroviários no país e a redução do montante do déficit de operação. ${ }^{3}$ Apontava o item "pessoal" como um dos alvos da redução, mas, contraditoriamente, reconhecia que as estradas de ferro padeciam da falta de pessoal especializado, "restando um punhado de técnicos abnegados" para dar conta de todas as funções, num período em que os técnicos e administradores já haviam migrado em massa para outros setores dos transportes ou da indús- 
tria nacional. A ferrovia deixava de ser setor de ponta na engenharia e administração nacionais (MVOP/RFFSA,1959, p. 37). Por outro lado, esses estudos cujos critérios de realização eram discutidos por especialistas, ${ }^{4}$ baseavam-se fortemente em estatísticas.

A evolução do déficit, segundo o Relatório, principalmente após a II Guerra Mundial, devia-se muito mais à política econômica, financeira e de transportes praticadas pelo governo do que propriamente a questões internas das empresas ferroviárias. Após a Guerra, boa parte das ferrovias encontrava-se com os equipamentos desgastados e obsoletos e não houve esforço para o reaparelhamento. ${ }^{5}$ Por outro lado,

uma política cambial de subvenção às importações, somada à de prioridade aos investimentos rodoviários, gradativamente reduziu a capacidade competitiva do sistema ferroviário, ao mesmo tempo que uma política de tarifas baixas diminuía, em termos reais, o preço cobrado pelas estradas. (MVOP/RFFSA, 1959, p. 39)

Dentre as soluções apontadas para esses e outros problemas, estava a necessidade de aumento da densidade do tráfego (considerando, doravante, a ferrovia para o transporte de grandes massas a longas distâncias) ${ }^{6}$ e a eliminação de ramais ou trechos ferroviários antieconômicos. ${ }^{7} \mathrm{O}$ tráfego de passageiros também era responsabilizado pelos déficits, argumentando-se que a RFFSA era obrigada a executar o serviço de passageiros em todas as suas linhas, mediante as mais baixas tarifas do mundo. $\mathrm{O}$ tráfego de passageiros representaria metade do trabalho total produzido na RFF, em unidades de tráfego, mas proporcionava "apenas" 20\% da receita (MVOP/RFFSA, 1959 , p. 47).

A ferrovia continuou sendo o meio de transporte mais importante para regiões beneficiadas por empresas ferroviárias, até a inauguração das estradas de rodagem que, geralmente, seguiam paralelas ao leito ferroviário. Com a intensificação do tráfego nessas estradas e nas marginais e com o crescimento da indústria automobilística, muitas regiões servidas pela ferrovia durante 60 anos começaram a deslocar sua preferência para as rodovias. Com o sucateamento crescente, os trens se atrasavam com freqüência e os acidentes tornavam-se rotina. A obsolescência do material rodante fazia os trens perderem velocidade, tornando o transporte ferroviário de bens perecíveis mais arriscado do que o pelas rodovias.

Os sucessivos governos brasileiros incentivavam o transporte rodoviário, com subvenções, impostos etc., alegando a ineficiência, o empreguismo, os déficits e a inexistência de capitais suficientes para a recuperação 
do sistema ferroviário. Em face dessa situação, montou-se um programa de erradicação dos "ramais antieconômicos", cuja orientação seguia os parâmetros da Comissão Mista Brasil-Estados Unidos (CMBEU) e que acabou sendo incorporado e aprofundado pela ditadura militar após 1964. Nesse processo de extinção, usado como justificativa para o fortalecimento dos ramais considerados rentáveis, foram arrancados mais de 10 mil quilômetros de trilhos. Desnecessário dizer que muitos locais ficaram sem transporte ou sem vias trafegáveis, aprofundando-se as disparidades regionais. Os trens de passageiros interregionais que resistiram anteriormente foram extintos na década de 1980; os demais foram desativados após a divisão da malha ferroviária e concedidos à iniciativa privada, com exceção da Estrada de Ferro Carajás, Amapá e E. F. Vitória a Minas, da CVRD, que ainda operam transportando passageiros. $\mathrm{O}$ transporte de passageiros ficou quase que exclusivamente restrito a alguns núcleos urbanos, ${ }^{8}$ gerenciados pela Companhia Brasileira de Trens Urbanos (CBTU), criada em 1984. A RFFSA prosseguiu sofrendo modificações administrativas. A ferrovia brasileira tornava-se, de fato, voltada principalmente ao transporte de cargas (minérios e produtos agrícolas de exportação), abandonando o transporte de passageiros, ou seja, voltada para o mercado externo, sem vinculação com uma política social mais abrangente.

\section{Processo de desestatização - Novas oportunidades de negóclos}

No site do Departamento Nacional de Infra-Estrutura de Transportes (DNIT), há um histórico em que se menciona um "processo de desestatização" constituído de um conjunto de ações realizadas no período de 1980 ao final de 1990, o qual desembocou na privatização da malha ferroviária nacional, em 1995. Ao mostrar o referido processo, retrospectivamente, afirma-se que, já nos anos 80 , não havia disponibilidade de verbas para melhorias no setor ferroviário, ${ }^{9}$ que passara por uma parcial recuperação em 1974-1978, em decorrência dos investimentos nos corredores de transporte e também dos desdobramentos do choque do petróleo, em 1973. Por isso, descartando-se o investimento estatal, surgiu a necessidade de concessão de serviços públicos de transporte de carga à iniciativa privada. Era o reinício de novo ciclo de mudanças institucionais, visando acelerar o padrão de acumulação.

Segundo Sérgio de Azevedo Marques, em um texto denso e repleto de dados e informações sobre o setor ferroviário, 
o crítico estado dessas ferrovias não permitiu senão a montagem de um novo aparato legal e institucional, visando à abertura da exploração ferroviária à iniciativa privada, como oportunidade de negócios, de um lado, e a possibilidade, de outro, do reerguimento do setor ferroviário, sob o modelo ideológico, centrado na reforma do Estado e na necessidade do incremento da eficiência global da economia, que ora se instala no país. (MARQUES, 1996, p. 5)

O projeto para as ferrovias, no âmbito da reforma do Estado era, pois, atrair novos investimentos, mas acentuando a característica que já vinha sendo definida: a de transporte de cargas e, especificamente, de determinadas cargas. Segundo Marques, no Brasil há uma concentração exagerada de produtos transportados pelos trilhos, que se organizam em cinco grupos: minérios de ferro, granéis agrícolas para exportação, combustíveis, produtos siderúrgicos e cimento. Desses, o minério de ferro representa $70 \%$ do volume transportado (MARQUeS, 1996, p. 16). Assim, o vínculo social do transporte ferroviário inter-regional foi se desvanecendo com as sucessivas reformas, culminando na extinção da RFFSA.

Em março de 1992, através do Decreto n. 473, o Governo Federal incluiu a RFFSA no Programa Nacional de Desestatização (PND). Aprovado em 1990, o PND respondia às fórmulas de saneamento financeiro propostas para países iberoamericanos por organismos internacionais, como o Fundo Monetário Internacional. ${ }^{10} \mathrm{Em}$ resposta à crise do keynesianismo e do Welfare State (que no Brasil só conhecemos na face desenvolvimentista), elaborava-se a idéia de que o Estado era mau administrador e pior ainda como empresário, daí a necessidade de que a atividade empresarial seja conduzida pela iniciativa privada: a "crise do Estado", conceito ligado à nova ideologia, foi o detonante para a formulação de políticas de ajuste liberais que buscavam a substituição da iniciativa pública pela privada (CARRAsco, 1998, p. 206). Acompanha essa ideologia a tendência de enaltecer setores não governamentais, do "terceiro setor", da "sociedade civil" ou de arenas supostamente públicas e não estatais, como contraposição ao burocratismo e ao corporativismo ${ }^{11}$ (Pereira; GraU, p. 16).

O BNDES, como gestor dos processos de privatização, em particular da RFFSA, elaborou a forma e as condições gerais para as concessões. Com pouco mais de 29 mil quilômetros de extensão, a malha ferroviária brasileira era operada por quatro empresas que respondiam por $95 \%$ do total de cargas transportadas. Três delas eram controladas pelo governo federal: Rede Ferroviária Federal S.A., Estrada de Ferro Vitória a Minas e Estrada de Ferro Carajás. Essas duas últimas pertenciam ao patrimônio da Companhia 
Vale do Rio Doce. A quarta operadora era a Ferrovia Paulista S.A. (FEPASA) que pertencia ao governo de São Paulo. ${ }^{12}$ A RFFSA foi dividida em seis malhas e procedeu-se aos leilões, de 1996 a 1998. A FEPASA foi privatizada em separado.

DESESTATIZAÇÃo DA RFFSA

\begin{tabular}{|c|c|c|c|c|}
\hline $\begin{array}{l}\text { MaLhas } \\
\text { REGIONAIS }\end{array}$ & $\begin{array}{c}\text { DATA } \\
\text { DO LEILÃo }\end{array}$ & CONCESSIONARIAS & $\begin{array}{c}\text { INfCIO } \\
\text { DA OPERAÇAO }\end{array}$ & $\begin{array}{c}\text { EXTENSĀO } \\
(\mathrm{KM})\end{array}$ \\
\hline Oeste & $5 / 3 / 1996$ & Ferrovia Novoeste S.A. & $1 / 7 / 1996$ & 1.621 \\
\hline Centro-Leste & $14 / 6 / 1996$ & $\begin{array}{l}\text { Ferrovia Centro- } \\
\text { Atlântica S.A. }\end{array}$ & $1 / 9 / 1996$ & 7.080 \\
\hline Sudeste & $20 / 9 / 1996$ & MRS Logística S.A. & $1 / 12 / 1996$ & 1.674 \\
\hline Tereza Cristina & $22 / 11 / 1996$ & $\begin{array}{l}\text { Ferrovia Tereza } \\
\text { Cristina S.A. }\end{array}$ & $1 / 2 / 1997$ & 164 \\
\hline Nordeste & $18 / 7 / 1997$ & $\begin{array}{l}\text { Cia. Ferroviária } \\
\text { do Nordeste }\end{array}$ & $1 / 1 / 1998$ & 4.534 \\
\hline Sul & $13 / 12 / 1998$ & $\begin{array}{l}\text { Ferrovia Sul-Atlântico } \\
\text { S.A. atualmente, } \\
\text { América Latina } \\
\text { Logística S.A. (ALL) }\end{array}$ & $1 / 3 / 1997$ & 6.586 \\
\hline $\begin{array}{l}\text { Paulista (ex- } \\
\text { FEPASA) }\end{array}$ & $10 / 11 / 1998$ & $\begin{array}{l}\text { Ferrovias Bandeirantes } \\
\text { S.A. }\end{array}$ & $1 / 1 / 1999$ & 4.236 \\
\hline \multicolumn{4}{|l|}{ TOTAL } & 25.895 \\
\hline
\end{tabular}

Fonte: RFFSA e BNDES. Apud Ferrovias/Histórico. DNIT: www.dnit.gov.br

O prazo de concessão das malhas foi de 30 anos, renováveis por igual período. Pelo contrato, as concessionárias obrigaram-se a pagar tanto pela exploração comercial do transporte ferroviário de cargas, quanto pelo uso dos equipamentos da RFFSA. A elas cabem também os investimentos, principalmente na manutenção das vias.

$\mathrm{O}$ ataque massivo à "ineficiência" do Estado e a exaltação à iniciativa privada abriu espaço para formas de concentração de capital e de favorecimento de interesses ainda mais violentos que anteriormente, o que se conjugou com demissão em massa de trabalhadores, extinção de empregos e retirada de direitos sociais arduamente conquistados. ${ }^{13}$ No caso das ferrovias, houve uma evidente concentração do setor pelos exploradores de minério. No caso da Ferrovia Centro Atlântica (FCA), conforme o site da empresa (www.fcasa.com.br), em 1996, a Malha Centro-Leste da Rede Ferroviá- 
ria Federal foi desestatizada, originando a Ferrovia Centro-Atlântica (FCA). Originalmente, a FCA foi consorciada pelos grupos Mineração Tacumã Ltda (empresa controlada pela CVRD), Ralph Partners, Railtex International Holdings Inc, Interférrea S.A. - Serviços Ferroviários e Intermodais, Judori - Administração, Empreendimento e Participações S.A., Companhia Siderurgia Nacional (CSN), Gruçai Participações S.A., Tupinambarana S.A. e Varbra S.A., muitos dos quais vindos de grandes empresas nacionais $\mathrm{e}$ com participação estrangeira. Voltada exclusivamente para a operação ferroviária de cargas, a FCA passou a desenvolver sua logística focada, principalmente, em granéis como a soja, derivados de petróleo e álcool combustível. A concessão foi fixada em cerca de $\mathrm{R} \$ 316$ milhões. A partir de agosto de 1999, a Companhia Vale do Rio Doce (privatizada em 1997) passou a ser líder do grupo de controle da Ferrovia Centro-Atlântica. Em setembro de 2003, autorizada pela Agência Nacional de Transportes Terrestres (ANTT), a Vale assumiu o controle da FCA, com $99,9 \%$ das ações, num processo em que uma mega-mineradora assumiu o seu próprio transporte. ${ }^{14}$

Após os leilões da malha ferroviária, "sobrou" uma empresa com uma enorme dívida, com cerca de 500 funcionários, patrimônios materiais e imateriais, tudo completamente à deriva. Em 7 de dezembro de 1999, o Governo Federal, com base na Resolução n. 12, de 11 de novembro de 1999 do Conselho Nacional de Desestatização e por intermédio do Decreto n. 3.277, dissolve, liquida e extingue a RFFSA. Enquanto se extinguia a Rede, criava-se a Agência Nacional de Transportes Terrestres (ANTT), doravante responsável pelos transportes rodoviário e ferroviário de cargas e passageiros. Criou-se também o Departamento Nacional de Infra-Estrutura de Transportes (DNIT), responsável pelo gerenciamento dos projetos e obras de infra-estrutura de transportes e pela administração do sistema de manutenção. Para isso, também, extinguia-se, além da RFFSA, o Departamento Nacional de Estradas de Rodagem (DNER), a Rede Federal de Armazéns Gerais Ferroviários S.A. (AGEF), Empresa Brasileira de Planejamento de Transportes e a Valec Engenharia (GEIPOT), Construções e Ferrovias. ${ }^{15}$

Num artigo que integra o número comemorativo dos 50 anos da revista Novos Estudos, do CEBRAP, Fernando Henrique Cardoso trata da reforma do Estado e das privatizações realizadas nos anos 90 , sob os seus mandatos no governo federal. Esclarece que, embora se refira a Estado e governo como se fossem a mesma coisa (segundo a tradição anglo-saxã), entende que governo "é o conjunto de instituições, mecanismos e pessoas que exercem poder, enquanto Estado refere-se às instituições e mecanis- 
mos que asseguram a dominação". Essa distinção é importante para entendermos a que Estado se refere e o sentido atribuído à "reforma". Defende, nessa reforma, uma gestão mais gerencial e menos burocrática. Nesse sentido, encontram-se as agências reguladoras, como a Anatel, para telecomunicações, Aneel, para energia elétrica e ANP, para o petróleo, "que substitutem as burocracias ministeriais - e os antigos lobbies nelas incrustados - por um grupo de pessoas indicadas pelo Executivo em bases de conhecimento técnico e competência administrativa e aprovados pelo Senado" (CARDoso, 1998, p. 10). Nessa versão, a racionalidade burocrática teria sido substituída pelo "gerenciamento técnico e competência administrativa", num espaço de neutralidade, em que a "ação pública" seria mais ampla e mais eficaz do que a ação estatal (p. 7). As agências seriam esses instrumentos de responsabilidade pública, fiscalizados pelo poder legislativo e não pela ação estatal. Esse seria, supostamente, um viés público (e democratizador) numa ação estatal cujo princípio é a dominação. Dicotomizar esses espaços talvez seja uma boa estratégia analítica para justificar novas ações estatais num avançado processo de acumulação, baseado na financeirização, sob a batuta de novos agentes.

Avaliando a política de ação regulatória e a formação das agências, Marcus André Melo analisa o formato desse modelo nos EUA: suas agências foram criadas durante três fases, com características distintas: no final do século XIX, nos anos 30 e 60. Durante o New Deal, "as novas agências detinham funções legislativas (grande autonomia para emitir normas), adjucantes (arbitravam conflitos entre as partes) e executivas (implementavam decisões administrativas)" (Melo, 2001, p. 57).

A crítica, formulada por muitos autores a esse formato, considerado autoritário (ou segundo o autor, portador de um "déficit democrático"), surge nesse país nos anos 70, evidenciando os "triângulos de ferro" formados por agências burocráticas, interesses organizados e comitês congressuais (QUIRK apud Melo 2001, p. 61). Segundo Melo, "a crítica principal era que o Judiciário e o Congresso não dispunham de mecanismos de controle efetivo sobre a burocracia pelo fato de não possuírem informações relevantes nem instrumentos de pressão adequados".

Percebe-se, então, que a criação de agências não só não foi uma inovação, como já possuía uma trajetória de experiências e críticas. É preciso, para sair das armadilhas do discurso ideologizado, investir no entendimento da complexidade das relações sociais. Segundo os aportes teóricos de Antonio Gramsci sobre o Estado ampliado, como espaço de embate constante de forças, o lugar da dominação não se encontra somente na socieda- 
de política propriamente dita, mas na própria sociedade civil. Isso contraria as apropriações mais recentes (à direita e à esquerda) do conceito de "sociedade civil" como contraponto à política e ao Estado. No pensamento de esquerda, em especial, Guido Liguori sintetiza as contribuições teóricas de Gramsci na análise da conjuntura atual, muito marcada pelos efeitos da "mundialização":

o fato de a cultura de esquerda ter substituído, já na passagem decisiva dos anos 70 para os anos 80 , a leitura da realidade baseada na divisão da sociedade em classes e na relação entre as classes por uma leitura baseada no tema da cidadania e dos direitos, foi e é, por si só, homólogo (e propedêutico) ao triunfo atual da "sociedade civil": neste processo, aliás, se efetiva em boa parte aquele triunfo do neoliberalismo que mencionei acima. (Liguori, 2000/2001, p. 42) ${ }^{16}$

Ao colocar as categorias de ampliação dos "direitos" e da "cidadania" como centrais, acaba-se por aderir a uma visão liberal e de fato também liberista, num momento em que, contrariando as vãs aparências, "o Estado, os Estados não só não parecem desaparecer, mas continuam sua dialética complexa com o econômico-social" (Liguori, 2000/2001, p. 50).

A criação das agências, por meio de Medidas Provisórias, veio acompanhar o processo de privatização de vários setores estratégicos na economia: transportes, telecomunicações, recursos minerais, siderurgia etc. Essa nova e aparente modernização, ou capítulos da revolução passiva à brasileira, é desvendada no seu significado mais amplo pelo venezuelano Edgardo Lander, num artigo publicado em coletânea presidida pelo ex-ministro Bresser Pereira, ${ }^{17}$ sobre a dita reforma do Estado. Contrastando boa parte das visões ali apresentadas, ele apresenta a seguinte análise:

Nos debates atuais sobre o social, sobre a sociedade civil, e sobre o público não estatal tende a haver, como pressuposto mais ou menos implicito, uma noção do social e de sociedade civil que tem sua origem nas formas históricas particulares nas quais se desenvolveu a sociedade civil européia. (LANDER, 1999, p. 478)

Além de localizar essa origem eurocêntrica da concepção de sociedade civil e do social, o autor analisa os limites do potencial democratizador da esfera pública não estatal, afirmando que qualquer coisa que se proponha sem uma 
democratização profunda dos principais instrumentos de interpretação e criação de sentido da sociedade contemporânea - a escola e os meios de comunicação social, são limitadas as possibilidade de se avançar em outros âmbitos da vida coletiva para maiores graus de democratização. (LANDER, 1999, p. 485)

E conclui:

dadas essas condições sociais da exclusão, hierarquização e desqualificação de todos esses diversos outros que não correspondem ao paradigma do cidadão urbano e moderno, é possível concluir que os desafios com que se defronta a construção da democracia no continente são muito mais complexos que os referentes às modalidades de organização do Estado ou aos mecanismos institucionais da participação cidadã. Dependendo de como se articule com os processos econômicos, políticos e culturais que se verifiquem no conjunto das sociedades contemporâneas, o fortalecimento da esfera pública não estatal pode significar um avanço democrático ou, pelo contrário, uma forma de legitimar a primazia neoliberal do mercado. (p. 485)

Houve reações diversas à extinção da Rede Ferroviária. O ideal democratizador, em amplo contraste com a prática política das Medidas Provisórias (MPs), não foi capaz de convencer amplos setores sociais: entidades preservacionistas, organizações de classe, vozes isoladas. Significava a liquidação de um valioso patrimônio, englobando capital humano, maquinários, estações, diversos bens móveis e imóveis, obras de infra-estrutura etc. Várias associações tentaram, por todos os meios, preservar a Rede, reivindicando a manutenção de seu papel, acrescido de novas funções, com sua inserção na estrutura do setor de transportes, como assessorias às agências criadas e ao próprio Ministério dos Transportes. Era essa, por exemplo, a reivindicação de três Federações, sediadas no Rio de Janeiro: Federação das Associações de Engenheiros Ferroviários (FAEF), Federação Nacional das Associações dos Ferroviários Aposentados e Pensionistas (FENAFAP) e Federação Nacional Independente dos Trabalhadores (FNITST) sobre Trilhos que, em julho de 1999, uniram-se e lançaram suas reivindicações na "Carta do Rio de Janeiro". Havia uma preocupação com notícias advindas da imprensa que envolviam "o futuro da RFFSA, anunciando a sua extinção, a curtíssimo prazo, sem que se tenha informação quanto ao equacionamento da questão de pessoal" (FAEF, FENAFAP e FNITST, 1999, p. 3). Tentava-se, então, salvar o possível nesse processo que se tornava uma avalanche, encontrando os trabalhadores e suas organizações ora enfraquecidos, ora comprometidos com o novo modelo. 
Embora não se soubesse exatamente o que estava acontecendo, nem seus possíveis desdobramentos, a não ser pelo que a imprensa noticiava, temia-se pelos ferroviários e pelo próprio transporte ferroviário. Após apresentar as reivindicações, as associações afirmam:

Dessa forma, a RFFSA e os ferroviários poderão alavancar a imediata e eficaz atuação dos órgãos que serão criados, que certamente é o que a Sociedade deseja, possibilitando que a ferrovia consiga crescer e aumentar sua participação na matriz de transporte da Nação, transformando-se, estrategicamente, em efetiva alternativa de transporte em graves situações como a ocorrida na recente paralisação nacional dos caminhoneiros. (FAEF, FENAFAP e FNITST, 1999, p. 3)

A concepção esboçada acima, da ferrovia enquanto transporte com vínculo social, voltado ao desenvolvimento da nação, era justamente o que estava sendo solapado no momento. As medidas tomadas no setor pretensamente buscavam a desoneração do Estado com os déficits ferroviários, o reconhecimento de sua incapacidade para o investimento e a perspectiva de atrair a iniciativa privada para a área. E "desonerar" significa justamente romper o vínculo social, não admitindo a necessidade de subsídios e adotando-se o critério mercadológico, segundo o qual o transporte, enquanto indústria, deve ser voltado ao lucro. E lucrar nesse setor significa transportar, essencialmente, cargas (muito) remuneradoras destinadas ao mercado exportador.

O processo de liquidação e extinção da RFFSA não foi ainda concluído (embora o DNIT e ANTT estejam em operação, comandando o setor) e tem encontrado resistências, sofrendo embargos e intervenções diversas. Em 6 de abril de 2005, o governo Lula da Silva tentou por fim à questão, também utilizando o recurso das MPs. Baixou as Medidas Provisórias n. 245, criando um fundo de $\mathrm{R} \$ 3,4$ bilhões para pagamento das dívidas da Rede, que chegavam a R\$ 14 bilhões e n. 246, que distribuía as competências anteriormente da Rede entre DNIT e ANTT, tratando da extinção definitiva da Rede Ferroviária. Editou também o Decreto n. 5.412 que, regulamentando as duas MPs, reestruturava o setor, estabelecendo competências e atribuições do DNIT e da ANTT. Todavia, o Plenário da Câmara rejeitou as referidas MPs, numa votação acompanhada por cerca de 400 ferroviários na galeria do plenário: "além de considerarem as MPs inconstitucionais, os deputados avaliaram que o fundo não seria suficiente para pagar as dívidas da Rede" (Debate sobre ferrovias volta ao começo, 23/6/2005). O tema retornou ao debate no âmbito do Programa de Aceleração do Crescimento (PAC), cal- 
cado no ideário das Parcerias Público Privadas (PPPs), pela edição da MP n. 353 , que recebeu 151 emendas, a maioria tratando de assuntos referentes a funcionários e bens da RFFSA (Thiago, 9/2/2007, p. A10).

O processo de desmonte da RFFSA atravessa os governos dos presidentes Fernando Henrique Cardoso e Luis Inácio Lula da Silva, em processo de continuidade e aprofundamento das medidas. Todavia, está inconcluso, devido à oposição à extinção da Rede e também a questões ligadas à condução do processo.

Houve várias intervenções do Ministério Público Federal, também pressionado por entidades ferroviaristas e preservacionistas, para inventariar e preservar o rico patrimônio sob a guarda da Rede Ferroviária. Por exemplo, em 25 de junho de 2003, por ocasião da realização do V Encontro Nacional do Ministério Público Federal sobre Meio Ambiente e Patrimônio Cultural, no Recife-PE, foi elaborada uma Recomendação à Comissão de Liquidação da Rede Ferroviária Federal, solicitando-lhe uma lista completa dos bens móveis e imóveis, com identificação daqueles de caráter cultural, os quais, a partir daí, não deveriam ser alienados sem o prévio parecer do IPHAN (MPF, 2003).

Em matéria do jornal Estado de S. Paulo, o Ministério Público é responsabilizado pela demora na liquidação da RFFSA, que não foi extinta $\mathrm{e}$ também não tem função operacional, mas consome milhões de reais/ano:

as tentativas de liquidação esbarraram na ação do Ministério Público, que reclama um inventário detalhado dos bens da estatal - o segundo maior patrimônio imobiliário da União. Há na Justiça mais de $30 \mathrm{mil}$ ações trabalhistas contra a empresa e as dívidas ultrapassam a casa de R\$ 5,5 bilhões.

O resultado das pendengas é que a Rede permanece ativa, administrando o nada com 474 funcionários. A estrutura consome milhões de reais por ano. Em 2005, foram R\$ 50 milhões, ou R \$4,2 milhões por mês, somente em gastos correntes. (TEREZA, 2006, p. B18)

Advoga-se a pressa, reclama-se das exigências do MP acerca de um inventário detalhado de bens que são, devemos lembrar, patrimônio público desperdiçado Brasil afora. Quanto aos funcionários, resumem-se a números. Outros capítulos ainda virão, já que o processo está inconcluso. Esse intrincado quadro (quase surrealista) é incrementado pelas denúncias de constantes investimentos do BNDES nas ferrovias, mas também de descumprimento de contratos e abandono do patrimônio arrendado, principalmente de linhas menos lucrativas. ${ }^{18}$ 
CONCLUSÃO

Enquanto no Brasil se extinguiam ramais e se abandonava o transporte de passageiros inter-regionais, a tecnologia ferroviária avançou rumo aos trens de alta velocidade, em vários países do mundo desde a década de 1960: em 1964, inauguração do trem bala japonês entre Tokio e Osaka, com velocidade média de $160 \mathrm{~km} / \mathrm{h}$; em 1979: TGV francês, com velocidade média de $213 \mathrm{~km} / \mathrm{h}$ (que atualmente pode alcançar $515 \mathrm{~km} / \mathrm{h}$ ) etc.

Nos últimos anos, têm sido realizados estudos para a implantação de Trens de Alta Velocidade (TAVs), ligando Rio-São Paulo-Campinas e também ligando Brasília a Goiânia. A cada crise aérea ou rodoviária, ressurgem os projetos ferroviários que ainda não se concretizaram. Sobre as demais possibilidades de trens inter-regionais, as concessionárias privadas da malha da RFFSA declaram que não estão interessadas no transporte de passageiros, tipo de operação não mais considerada rentável. Em matéria publicada na Folha de S. Paulo, sintomaticamente no caderno "Dinheiro", ao lado de uma reportagem de meia página sobre estudos do BNDES para a retomada de alguns trechos ferroviários, o diretor executivo da Associação Nacional dos Transportadores Ferroviários (ANTF), Rodrigo Vilaça, afirmou sobre a questão: "Isso é saudosismo" (MedinA, janeiro de 2005). Anteriormente, em 2003, foi lançado, também sem sucesso, o "Plano Nacional de Revitalização Ferroviária”, que pretendia arrecadar R $\$ 8$ bilhões de reais (investimentos públicos e privados) para a recuperação das ferrovias brasileiras(WERNECK, 2003, p. 23). A não ser a reativação de alguns ramais para a indústria do turismo, o efetivo transporte de passageiros a médias e longas distâncias ainda não se concretizou. Se acontecer, será em alguns trechos "rentáveis", o que poderá constituir um novo capítulo na história ferroviária brasileira. Como se vê, não existe uma política efetiva e integrada de transportes no país. Nessas circunstâncias, cabe perguntar: em que estação chegará esse trem?

\section{YEARS OF RAILWAYS IN BRAZIL: WHERE DOES THIS TRAINS LEAD TO?}

ABSTRACT: The aim of this paper is to investigate the major changes occurred in Brazil's railway policy regarding the interregional transport of passengers and loads. The establisment of Rede Ferroviária Federal (Brazil's Railway network) in 1957, unifying eighteen private companies, has had a response from the post 1990 government through the reprivatization of the network and the reformulation of the control agencies and the policies of execution. What interests do these changes serve? What are the characteristics of the Brazilian railway policy as established

História Revista, Goiânia, v. 13, n. 1, p. 45-69, jan./jun. 2008 
within the period above? These are complex issues, that involves the state form (in terms of political society), its relation with the market, the financial globalization question, the internal panorama of class struggle etc., all of which requiring more detailed studies of the railway sector in the development of the capitalism in Brazil.

KEY WORDS: Transport policy, railways, Rede Ferroviária Federal S.A.

\section{NOTAS}

1 Eis alguns exemplos desse debate: Iniciado debate sobre a transformação das redes ferroviárias em sociedades anônimas. Revista do Clube de Engenharia, jun. 1952, p. 183-185; Transformação das ferrovias em sociedades anônimas. Revista do Clube de Engenharia, abr. 1953, p. 157-161. O debate girava em torno da necessidade de se unificar a administração ferroviária, "eliminar influências políticas" na administração, superar os déficits, eliminar ramais deficitários. Por outro lado, havia críticas à organização da Rede como sociedade de economia mista. Dizia o engenheiro Francisco Bonifácio Lafayette de Andrada que, ainda que o capital fosse predominantemente estatal, as empresas detentoras do capital restante poderiam influenciar no transporte de mercadorias que lhes pertenciam, prejudicando os próprios estados servidos pelas ferrovias. Um outro exemplo: Transformação das ferrovias em sociedades anônimas. Revista do Clube de Engenharia, set. 1953, p. 29-35 e 49. Esse prognóstico não foi cumprido na época, mas aconteceu nos anos 90 , com as concessões às empresas privadas e a posterior liquidação da RFFSA, como veremos adiante.

2 Estradas incorporadas à RFFSA: Rede de Viação Cearense (incorporando a E. F. Baturité e a E. F. Sobral); Rede Ferroviária do Nordeste (ex-Great Western); Viação Férrea Leste Brasileiro; Estrada de Ferro Leopoldina; Estrada de Ferro Central do Brasil (ex-Pedro III), Rede Mineira de Viação (incorporando a E. F. Oeste de Minas e a Rede Sul Mineira); Estrada de Ferro Noroeste do Brasil; Rede de Viação Paraná-Santa Catarina e Viação Férrea do Rio Grande do Sul.

3 O estudo dos déficits multiplicava-se nos relatórios de diversos grupos de trabalho, ocupava a imprensa especializada e os discursos dos "especialistas" nos transportes. Segundo a Revista Ferroviária: "o sistema deficitário das ferrovias brasileiras foi, ao mesmo tempo, causa e efeito da não realização dos investimentos necessários à expansão e melhoria da capacidade de transporte [...]". Ago. 1971, p. 27. Capistrano do Amaral, presidente da Associação Ferroviária Brasileira (AFB), afirmava que o déficit já havia se tornado "slogan", definindo-se como causa da grande desgraça nacional e que "o único modo de extingui-lo é a extinção do próprio sistema ferroviário, o qual, dizem os espertos e acreditam os ingênuos, "é a técnica obsoleta substituível pelo transporte rodoviário em todas as suas aplicaçôes". Criticava, assim, a idéia de "déficit" e 
propunha o reaparelhamento das ferrovias, deixando às rodovias o tráfego leve de distribuição. "Trem é a solução". Revista Ferroviária, Rio de Janeiro, ago. 1967, p. 20. SEDOC/RFFSA.

4 De acordo com Alain Abouchar, Professor Assistente de Economia na Universidade da Califórnia e, na época, Coordenador do Setor de Transportes do Escritório de Pesquisa Econômica Aplicada, do Ministério do Planejamento e Coordenação Econômica, as estatísticas brasileiras de transportes estavam sob suspeita. Para esse autor, a pesquisa era insuficiente pois não apurava as origens e destinos do transporte ferroviário, por Estado ou região e por mercadoria. As ferrovias também não registravam de onde procediam as cargas que se destinavam às suas estações. Portanto, essas e outras dificuldades dificultariam um planejamento racional porque limitavam bastante os dados disponíveis para o analista e perturbavam a interpretação das outras estatísticas. Abouchar, Alain. Deficiências das Estatísticas Brasileiras de Transporte. Ferrovia. São Paulo, mar. 1968, p. 40. SEDOC/RFFSA.

5 Em termos estritamente contábeis, as únicas empresas rentáveis em 1952, eram Companhia Paulista, a Santos-Jundiaí, a Sorocabana e a Vitória-Minas. Portanto, aquelas concentradas em áreas produtoras de café e minérios (CARRASCO, 1998, p. 204).

6 O lema: "transporte de grandes massas a grandes distâncias" era encampado pelas administrações regionais, excluindo grande parte dos serviços prestados pelas ferrovias, incluindo o transporte de passageiros e de cargas em pequenas distâncias.Ou seja, a tendência era aprofundar o transporte voltado ao mercado exportador, de grandes tonelagens de cargas em quilometragens cada vez maiores. Essa tendência aprofundou-se durante a Ditadura Militar, sendo criado, em 1972, sob a regência do Coronel Mário Andreazza no Ministério dos Transportes (criado em 1967, em substituição ao MVOP), o Programa Corredores de Exportação, envolvendo também os Ministérios da Fazenda e Planejamento, sinal de sua prioridade. Objetivava-se criar um sistema integrado de transportes convergindo aos principais portos: Santos (SP), Paranaguá (PR), Tubarão(Vitória-ES) e Rio Grande (RS). Os planos envolvendo a recuperação de ferrovias são, doravante, direcionados para esse sentido, principalmente para as ferrovias dedicadas ao transporte de minérios, produtos agrícolas e combustiveis.

7 Essa questão aparece como prioritária em todos os Relatórios da RFFSA, até 1974, quando se encerra a consulta.

8 Os sistemas de trens de subúrbio surgiram como desdobramento dos de trens de passageiros de longa distância, dedicando-se a prestar atendimento às localidades situadas nas zonas de expansão urbana próximas às áreas centrais das cidades que possuíam serviços ferroviários. Por constituírem uma dinâmica diferenciada, os serviços de subúrbio foram separados dos de longa distância e retirados também da administração central da RFFSA. Informação disponível 
no site da Associação Nacional de Transporte Público: $<$ www.antp.com.com.br $>$.

9 A extensão total da rede ferroviária declinou, de $31.366 \mathrm{~km}$ em 1970 para 29.778 km em 1980 e, em 1986, 29.613 km. Houve uma diminuição geral do pessoal empregado, de locomotivas e de vagões em operação, num contínuo processo de esvaziamento (NATAL, 1991, p. 283). Há também um sucateamento brutal no transporte suburbano ferroviário, devido ao aumento no número de passageiros e quase nenhum investimento.

10 Lei n. 8.031, de 12 de abril de 1990. Art. $1^{\circ}$ É instituído o Programa Nacional de Desestatização, com os seguintes objetivos fundamentais: I - reordenar a posição estratégica do Estado na economia, transferindo à iniciativa privada atividades indevidamente exploradas pelo setor público; II - contribuir para a redução da dívida pública, concorrendo para o saneamento das finanças do setor público; III - permitir a retomada de investimentos nas empresas e atividades que vierem a ser transferidas à iniciativa privada; IV - contribuir para a modernização do parque industrial do País, ampliando sua competitividade e reforçando a capacidade empresarial nos diversos setores da economia; V - permitir que a administração pública concentre seus esforços nas atividades em que a presença do Estado seja fundamental para a consecução das prioridades nacionais; VI - contribuir para o fortalecimento do mercado de capitais, através do acréscimo da oferta de valores mobiliários e da democratização da propriedade do capital das empresas que integrarem o Programa.

11 Segundo Bresser Pereira e Nuria Grau o espaço do setor público não estatal é também o espaço da democracia participativa ou direta, ou seja, é relativo à participação cidadã nos assuntos públicos. $\mathrm{O}$ público não estatal é formado por organizações ou formas de controle "públicas" porque voltadas ao interesse geral; são "não estatais porque não fazem parte do aparato de Estado, seja por não utilizarem serviço público, seja por não coincidirem com os agentes políticos tradicionais. (Pereira e Grau, p. 16) Bresser Pereira foi um dos agentes centrais do processo de privatização: em 1995, depois de ocupar a tesouraria da campanha de Fernando Henrique Cardoso para a presidência da república, assumiu o Ministério da Administração Federal e Reforma do Estado, onde comandou a Reforma da Gestão Pública de 1995. Informação disponível em Bresser Pereira Website: <www.bresserpereira.org.br>.

12 A criação da FEPASA (Lei n. 10.410/SP, 1971) pelo Governo do Estado de São Paulo, unificou as cinco empresas, em torno de 5 mil quilômetros: Companhia Paulista de Estradas de Ferro, Estrada de Ferro Sorocabana, Estradas de Ferro Araraquara, Companhia Mogiana de Estrada de Ferro e Estrada de Ferro São Paulo-Minas.

13 A América Latina Logística (ALL) parece ser a empresa que mais demitiu: em um único dia (3/3/97) cerca de 2800 dos 6900 empregados na regional SR5 que 
abrange o Paraná e Sta Catarina foram dispensados. A demissão foi em massa: mais de 1/3 do total dos servidores que trabalhavam por longos anos em atividades específicas: maquinistas, agentes de estação, manobradores, assistentes de tração, artífices de manutenção e outros. Denúncia ao Ministério Público do Trabalho $9^{a}$ Região, pelo SINDIMAFER, Sindicato dos Maquinistas Ferroviários do Estado do Paraná e Sta Catarina, através da advogada Dra. Clair da Flora Martins, contra a América Latina Logística do Brasil S.A. (ALL) ao Ministério Público, denunciando a demissão imotivada e arbitrária de milhares de ferroviários após a privatização da RFFSA. Disponível em: $<$ www.dra.clair.nom.br>.

14 Segundo indicações do jornal Valor, o governo Lula da Silva está preocupado com o alto custo dos fretes ferroviários e pretende editar medidas para incentivar a competição entre as empresas. Acontece que o setor, após a privatização, é dominado por três empresas: CVRD, CSN e ALL, que não competem entre si e estabelecem o preço quase de igual para igual com os fretes rodoviários. A pressão advém de setores ligados ao agronegócio, visando baixar o frete de seus produtos (minoritários diante do minério transportado) e ter opções de escoamento. RitTNER, Daniel. Governo quer mais competição entre ferrovias. Valor, 25, 26 e 27 jan. p. A3.

15 A criação de agências reguladoras no Brasil tem sido estudada nas próprias agências e no BNDES, em comissões internas, envolvendo profissionais principalmente na área da Administração. A reflexão acadêmica sobre o tema ainda está se constituindo.

16 Remetendo-se à discussão entre Benedetto Croce e Luigi Einaudi, Liguori diferencia "liberismo" e "liberalismo": "O primeiro termo é habitualmente usado em âmbito econômico, o segundo no discurso histórico-político, e portanto parece implicitamente mais moderado que o primeiro" (2000/2001, p. 45).

17 Foram trabalhos apresentados no Congresso do Centro Latino Americano de Administração para o Desenvolvimento (CLAD), sobre a reforma do Estado e da Administração Pública, realizado no Rio de Janeiro, em 1996.

18 Citaremos apenas alguns exemplos. Sobre saque de trilhos: FABRINI, Fábio. Trilhos saqueados. Estado de Minas, 22 maio 2005, Gerais, p. 27. Nas colunas de Elio Gaspari, falava-se até em reestatização, devido ao não cumprimento de contrato por operadoras. O foco, nessa reportagem, era a Novoeste, trecho Campo Grande-Cuiabá: A reestatização começará pelas ferrovias. Folha de S. Paulo, domingo, 10 ago. 2003, p. A14. E também sobre não cumprimento de metas contratuais: Santos, Chico. Ferrovias continuam dependuradas no BNDES. Folha de S. Paulo, 28 abr. 2002, p. B5.

\section{REFERÊNCIAS}

Araúto, Tânia Bacelar de. Elogio à diversidade regional. In: Benjamim, César et al. Visões da crise. Rio de Janeiro: Contraponto, 1998.

História Revista, Goiânia, v. 13, n. 1, p. 45-69, jan./jun. 2008 
Cardoso, Fernando Henrique. Notas sobre a reforma do Estado. Novos Estudos, Cebrap, São Paulo, n. 50, mar. 1998, p. 5-12.

Carrasco, Angel Rodrigues. El ferrocarril y la economía en Brasil. In: FernándeZ, Jesús Sanz (Coord.). Historia de los ferrocarrilles de Iberoamerica (1837-1995). Madrid: CEDEX/CEHOPU/Fundación de los Ferrocarrilles Espanõles, 1998, p. 169-210.

Dourado, Anísio Brasileiro de Freitas. Aspectos sócio-econômicos da expansão e decadência das ferrovias no Brasil. Ciência e Cultura, v. 36, n. 5, p. 733-736, maio 1984.

Grau, Nuria Cunill; Pereira, Luis Carlos Bresser. Entre o Estado e o Mercado: o público não estatal. In: . (Orgs.). O público não estatal na reforma do Estado. Rio de Janeiro: Editora da Fundação Getúlio Vargas, 1999.

LANDER, Edgardo. Limites atuais do potencial democratizador da esfera pública não estatal. In: Pereira, Luis Carlos; Grau, Nuria Cunill (Orgs.). O público não estatal na reforma do Estado. Rio de Janeiro: CLAD/FGV, 1999. p. 453-490.

Liguori, Guido. O pensamento de Gramsci na época da globalização. Educação em foco: revista de educação. Gramsci: 100 anos. UFJF/Faculdade de Educação/ Centro Pedagógico Educação em foco, v. 5, n. 2, set./fev., 2000/2001. p. 33-52.

MARQUES, Sérgio de Azevedo. Privatização do Sistema Ferroviário Brasileiro. Brasília, agosto de 1996. Disponível em: <www.ipea.gov.br/pub>.

MARTINS, Margareth Guimarães. Caminho da agonia: a Estrada de Ferro Central do Brasil - 1908-1940. 1985. Dissertação (Mestrado em História) - Universidade Federal do Rio de Janeiro, Rio de Janeiro, 1985.

Meirelles, Fernanda; Oliva, Rafael. Delegação e controle político das agências reguladoras no Brasil. RAP, Rio de Janeiro 40(4), p. 545-565, jul./ago. 2006. Disponivel em: <www.capes.gov.br/periodicos $>$.

Melo, Marcus André. A política da ação regulatória: responsabilização, credibilidade e delegação. Rev. Bras. Ci. Soc. [online]. 2001, v. 16, n. 46 [citado 2008-02-15], p. 56-68. Disponível em: 〈http://www.scielo.br/scielo.php >.

NATAL, Jorge Luis Alves. Transporte, ocupação do espaço e desenvolvimento capitalista no Brasil: história e perspectivas. Campinas, SP: 1991. Tese (Doutoramento em Economia) - Universidade Estadual de Campinas, Campinas, 1991.

PACHeCO, Regina Silvia. Regulação no Brasil: desenho das agências e formas de controle. Rev. Adm. Pública, Rio de Janeiro, v. 40, n. 4, 2006. Disponível em: <http:/ /www.scielo.br/scielo>.

PAULA, Dilma Andrade de. Fim de linha. A extinção de ramais da Estrada de Ferro Leopoldina, 1955-1974. 2000. Tese (Doutorado em História) - Universidade Federal Fluminense, Niterói, 2000. 
O futuro traído pelo passado: a produção do esquecimento sobre as ferrovias brasileiras. In: FENELON, Déa Ribeiro et al. (Orgs.). Muitas memórias, outras histórias. São Paulo: Olhos D’água, 2004. p. 41-67.

Ferrovias e rodovias: o dualismo na política de transportes no Brasil. In: MENDONÇA, Sonia Regina de (Org.). Estado e historiografia no Brasil. Niterói: EdUFF, 2006. p. 209-230.

SAES, Flávio A. Marques de. As ferrovias de São Paulo, 1870-1940. Expansão e declínio do transporte ferroviário em São Paulo. São Paulo: Hucitec, 1981.

\section{Fontes citadas}

Abouchar, Alain. Deficiências das Estatísticas Brasileiras de Transporte. Ferrovia, São Paulo, mar. 1968, p. 40.

Brasil. Lei n. 8.031, de 12 de abril de 1990. Programa Nacional de Desestatização PND. Disponível em: <www.legislacao.planalto.gov.br>.

Brasil. Decreto n. 5.412, de 6 de abril de 2005. Regulamenta a Medida Provisória n. 246, de 6 de abril de 2005. Diário Oficial [da] República Federativa do Brasil, Brasília-DF, de 7/4/2005, Edição n. 66.

DeBate sobre ferrovias volta ao começo. Gazeta do Povo -PR, 23/6/2005. Transcrito pela Revista Ferroviária, 23/6/2005, clipping de notícias.

Fabrini, Fábio. Trilhos saqueados. Estado de Minas, 22 de maio de 2005, Gerais, p. 27.

FAEF, FENAFAP e FNITST. Carta do Rio de Janeiro. Rio de Janeiro, julho de 1999, p. 3. Arquivo da Associação de Engenheiros Ferroviários. Rio de Janeiro.

GASPARI, Elio. A reestatização começará pelas ferrovias. Folha de S. Paulo, domingo, 10 de agosto de 2003. p. A14.

GEIPOT/COVERDALLE \& COLPITTS. Estudo de Transportes no Brasil, I Fase, v. 2, 1967. SEDOC-Setor de Documentação/RFFSA.

MVOP/RFFSA. Relatório anual de 1959. Rio de Janeiro, 1960. SEDOC/RFFSA.

Procuradoria Geral da República/Ministério Público Federal. Recomendação. $V$ Encontro Nacional do MPF sobre Meio Ambiente e Patrimônio Cultural. Recife, 25 jun. 2003.

RitTNER, Daniel. Governo quer mais competição entre ferrovias. Valor, 25, 26 e 27 jan. p. A3.

SANTOS, Chico. Ferrovias continuam dependuradas no BNDES. Folha de S. Paulo, 28 abr. 2002. p. B5.

História Revista, Goiânia, v. 13, n. 1, p. 45-69, jan./jun. 2008 
TereZA, Irany. A agonia sem fim da rede ferroviária. O Estado de S. Paulo, 28/5/ 2006. Economia \& Negócios, p. B18. Disponível na Biblioteca virtual do senado, seção 4. periódicos: <www.senado.gov.br>.

THIAGO, Jayme. MP que extingue a Rede Ferroviária é a campeã de emendas ao PAC. Valor Econômico, São Paulo, 9/2/2007, Política, p. A10. Disponível em: Biblioteca Digital do Senado Federal <www2.senado.gov.br>.

TREM é a solução. Revista Ferroviária, Rio de Janeiro, ago. 1967. SEDOC/RFFSA.

MedinA, Humberto. Governo tenta reativar trens de passageiros. Folha de S. Paulo, Caderno Dinheiro, 9 jan. 2005.

WERNECK, Lourival. Todos sonham com a volta do trem. Estado de Minas, Domingo, 14 set. 2003. p. 21-23.

\section{Sites consultados}

ANTP - Associação Nacional dos Transportes Públicos: <www.antp.org.br>.

ANTT - Agência Nacional de Transportes Terrestres: <www.antt.gov.br>.

BRESSER Pereira Website: <www.bresserpereira.org.br>.

CÂMARA dos Deputados: <www.camara.gov.br>.

DNIT - Departamento nacional de Infra-Estrutura de Transportes: $<$ www.dnit.gov.br $>$.

FCA - Ferrovia Centro Atlântica As: <www.fcasa.com.br >.

REVISTA Ferroviária: <www.revistaferroviaria.com>.

SENADO Federal: <www.senado.gov.br >. 